\title{
No Trust is Hybrid: Reply to Faulkner
}

\author{
Harold W. Noonan ${ }^{1}$
}

Received: 11 March 2020 / Revised: 6 January 2021 / Accepted: 28 January 2021 /

Published online: 12 February 2021

(c) The Author(s) 2021

\begin{abstract}
There is a well-developed literature on trust. In his important article Faulkner (Analysis, 75(3), 424-429, 2015) distinguishes three-place, two-place and one-place trust predicates. He then argues that our more basic notions of trust are expressed by the one-place and two-place predicates. Three-place trust, contractual trust, is not fundamental. This matters. Having a clear understanding of our concepts of trust is important. The most important assumption of Faulkner's argument is that the notion of trust expressed by the three-place predicate is not attitudinal; it is a 'metaphysical hybrid of attitude and action'. I argue that this is wrong. All three notions are attitudinal and no reason exists to deny that the one-place and two-place notions derive from the three-place one. Once one rejects Faulkner's assumption that the threeplace notion can be separated off from the others as a metaphysical hybrid argument for the priority of the one-place and two-place notions collapses.
\end{abstract}

Keywords Trust · Three-place · Contractual · Metaphysical hybrid · Faulkner · Attitude

In his important article Faulkner (2015) distinguishes, as is standard, three-place, two-place and one-place trust predicates. He then argues, very much non-standardly, that the basic notions of trust are those expressed by the one-place and two-place predicates. Three-place trust, contractual trust, is not the fundamental form from which the others must be derived. But why does this matter? First, because we need to be clear about our concepts of trust in order to understand our engagement with others since we constantly employ these concepts in describing this. Secondly, because trust has moral significance. We cannot understand the moral implications of our social intercourse without taking it into account. Thirdly, because trust is not just something for philosophers to study (see Faulkner's references). Faulkner's conceptual contention thus matters.

Harold W. Noonan

harold.noonan@nottingham.ac.uk

1 Department of Philosophy, University of Nottingham, Nottingham NG72RD, UK 
The most important assumption of his argument is that whereas the two-place and one-place notions of trust are 'purely atitudinal' this is not true of the notion of trust expressed by the three-place predicate. Rather, three-place trust is a 'metaphysical hybrid' of attitude and action. It is metaphysically necessary that three-place trust have an action component as well as an attitude component; that is what distinguishes it from one-place and two-place trust.

I argue that this is wrong. Three-place trust can be present without action, though its presence may, of course, be accompanied by or cause action. It is not, of its metaphysical nature, a hybrid. Hence there is no good reason given by Faulkner to deny that the two-place and one-place notions are derivative from the three-place notion. Once one rejects Faulkner's assumption that the three-place notion is metaphysically hybrid, and thus contrasts with the others, the rest of his argument that the one- and two-place notions are basic also collapses.

The notion of contractual trust is expressed by the three-place predicate ' $\mathrm{X}$ trusts $\mathrm{Y}$ to $\mathrm{V}$ ', the notion of trust in someone by the two-place predicate ' $\mathrm{X}$ trusts $\mathrm{Y}$ ', and the one-place notion by ' $\mathrm{X}$ is trusting' (there is also the notion of being trustworthy returned to below). Faulkner's claim is that we cannot understand the second and third notions in terms of the first or regard them as reducible to the first. My claim is that, for all he argues, we can. Specifically, I wish to say that Faulkner has not refuted the following claims. When all facts expressible in the form ' $\mathrm{X}$ trusts $\mathrm{Y}$ to $\mathrm{V}$ ' are in, the truth-values, if any, of all statements of the form ' $\mathrm{X}$ trusts $\mathrm{Y}$ ' and ' $\mathrm{X}$ is trusting' are determined. And when all facts of the form ' $\mathrm{X}$ correctly trusts $\mathrm{Y}$ to $\mathrm{V}$ ' are in, the truth-values, if any, of all statements of the form ' $\mathrm{X}$ is trustworthy' are determined (in each case, given an appropriate context).

The main assumption behind Faulkner's contrary argument is that three-place trust, unlike its lower place brethren, is, as a matter of metaphysical necessity, a hybrid incorporating an action component - of X's relying on Y to V - and so the three-place predicate is not a direct description of an attitude (" $\mathrm{X}$ trusts $\mathrm{Y}$ to [V]" is a metaphysically hybrid notion insofar as it describes an action ... and says of that that it is done with and because of a certain attitude' (2015: 424)).

This is mistaken. It is not metaphysically necessary that three-place trust has an action component since it can occur without one (Faulkner follows Hawley (2014) in his account of three-place trust, so counterexamples to him are equally counterexamples to Hawley.).

Two examples. I may trust a seller to deliver reliably to his customers, perhaps on the basis of my personal acquaintance with him, but never buy from him (maybe because he doesn't sell what interests me). My trusting the seller to deliver reliably is, in this case, merely a matter of my having a certain sort of conjunctive belief: that he is committed to doing so and can be relied upon to meet that commitment because he recognises it as such. No action component is present. My having the conjunctive belief, of course, involves a disposition to act in certain ways given other beliefs and desires, but so does any belief, that it is raining, for example, or that my umbrella is

\footnotetext{
${ }^{1}$ Equivalently, to anticipate, all facts of the form ' $\mathrm{Y}$ is committed to $\mathrm{V}$-ing and can be relied upon to meet that commitment because he recognises it as such'.
} 
waterproof. My conjunctive belief is no more thereby constituted a metaphysically hybrid entity than my belief that it will rain or that my umbrella is waterproof.

Second case. I decide to throw a party. I buy in the necessary provisions and ring round my friends to invite them. I call Tom and tell him I'm throwing a party. Before I can say more he offers to get in the drinks. I think I can't refuse since he will take it as a rebuff if I do. I know he is in a fragile psychological state and needs to feel needed (elaborate for yourself). So I accept (I know he can easily afford the money). At the end of the phone call, I believe that he is committed to buying the drinks and (because I know him well) that he can be relied upon to meet that commitment because he recognises it as such. I am in no sense reliant on him to buy the drinks. There is no 'act of reliance' present. However, if contrary to my expectations, he doesn't buy the drinks, I will be disappointed in him: he will have shown himself not to be the man I thought he was (the same may be true of my attitude to the seller in the first case if I find out that he is letting down his customers). ${ }^{2}$ I trust him to buy the drinks though I do not rely on him to do so.

Compare case three. I ring another friend, Dick, and tell him about the party. Before I can say more he offers to supply the cheesy bits (I seem to have needy friends). When he does so I realise, to my horror, that that is the one thing I have forgotten to get. I eagerly accept. At the end of the phone call, I believe that he is committed to buying the cheesy bits and (because I know him well) that he can be relied upon to meet that commitment because of his recognition of it. If, contrary to my expectations, he does not do so, I will be disappointed in him: he will have shown himself not to be the man I thought he was. I trust him to buy the cheesy bits and, as it happens, am also reliant on him doing so.

Contrast case four, described by Hawley. I have a colleague, Harry, who regularly brings in a packed lunch. He always prepares too much and leaves what he does not eat (which is ample) in the communal kitchen to be disposed of. Having cottoned on to this and being a skinflint, I adopt the practice of lunching on Harry's leftovers. I no longer even bring in money so I could buy lunch. I trust Harry to provide me with lunch. But this is just trust as mere reliance. I trust Harry as I trust the bookshelf to hold my books, or my dog to clear up the mess if I drop food on the floor. I may be disappointed if Harry reduces the size of his packed lunch, but I will not be disappointed in him: he will not have shown himself not to be the kind of man I thought he was in any way that will affect my attitude to him unfavourably. The previous cases can easily be distinguished from the fourth. In the fourth case I do not have the conjunctive belief that Harry has a commitment to provide me with lunch and can be relied upon to do so because he recognises that commitment as such. I merely believe that he can be relied upon to provide my lunch and rely on him doing so. The first three cases are all cases of contractual trust, in the third case accompanied by reliance. The fourth case involves reliance but is not a case of contractual trust. Contractual trust need not involve reliance and non-contractual trust may or may not.

\footnotetext{
2 The same will be true if I in fact do buy from the seller and so rely on him. In this case I will be disappointed if I do not receive my purchase, but I will be no more disappointed in him than I will if I learn, when I do not buy from him, that he is letting down customers.
} 
Since Faulkner's thesis about contractual trust is a thesis about its metaphysically necessary nature, hypothetical counterexamples refute it. In some cases all that is present when contractual trust is present is just a conjunction of beliefs of the form: $\mathrm{X}$ believes that $\mathrm{Y}$ has a commitment to $\mathrm{V}$-ing and also believes ${ }^{3}$ that $\mathrm{Y}$ can be relied upon to meet that commitment because he recognises it as such. ${ }^{4}$ Of course, in some cases action may also be present as well as the conjunction of beliefs and may be caused by the conjunction, but that is not necessary for contractual trust.

Once this is seen, I think, Faulkner's arguments for the non-derivativeness of the two-place and one-place notions from the three-place notion of trust can be seen to be less than convincing - they presuppose his claim that contractual trust is metaphysically hybrid.

Putting this claim aside, Faulkner points to no phenomenon that cannot be explained with the three-place notion of trust taken as basic.

Faulkner presents five 'pieces of evidence', or arguments. His first, with the false assumption that contractual trust is a metaphysical hybrid removed, is that ' $\mathrm{X}$ trusts $\mathrm{Y}$ ' does not mean 'For all V, X trusts $\mathrm{Y}$ to $\mathrm{V}$ ', or 'For some V, X trusts $\mathrm{Y}$ to $\mathrm{V}$ ' or 'For all actions $\mathrm{V}$ of type $\mathrm{R}, \mathrm{X}$ trusts $\mathrm{Y}$ to $\mathrm{V}$ ' for some restricted range of actions $\mathrm{R}$. But the obvious response is that the range of actions for which it must be true that $\mathrm{X}$ trusts $\mathrm{Y}$ to $\mathrm{V}$ for it to be true that $\mathrm{X}$ trusts $\mathrm{Y}$ is contextually determined. My trusting my son consists in my trusting him to $\mathrm{V}$ for some significant range of actions, i.e., for some significant range of actions my believing that he is committed to $\mathrm{V}$-ing and that he can be relied upon to $\mathrm{V}$ because of his recognition of the commitment - the significant range being actions directed towards the well-being of the family, such as giving me a lift. Whether the statement that I trust my son, uttered in a context, is true or not, will be fixed by the totality of facts: $\mathrm{X}$ trusts $\mathrm{Y}$ to $\mathrm{V}$ where $\mathrm{I}=\mathrm{X}$ and my son $=$ Y.

Similarly, the argument Faulkner gives that the one-place predication ' $\mathrm{X}$ is trusting' is more fundamental even than the two-place one (and hence, the three-place one) reduces to the claim that it is not equivalent to the claim: for all $\mathrm{Y}, \mathrm{X}$ trusts $\mathrm{Y}$. But I cannot see that this supports his contention, which he expresses as 'the heart of our notion of trust seems to be simply an attitude of trust, which may, but need not, take specific persons as its objects, and which can support, but need not, the act of relying on persons' (my italics). The reference to 'attitude' here and to the 'act' of relying on persons is probably doing a lot of work in Faulkner's view, and if I am right must be discounted since it presupposes that the three-place notion is metaphysically hybrid.

But setting that aside, we do talk of being trusting, too trusting and not trusting enough. What can give such statement the truth-values they have except facts of the form: $\mathrm{X}$ trusts $\mathrm{Y}$ (and ultimately of the form: $\mathrm{X}$ trusts $\mathrm{Y}$ to $\mathrm{V}$ )?

\footnotetext{
${ }^{3}$ Or maybe, hopes: I can decide to trust my child's promise (though I can also decide to believe my child's statement). But whether the attitude involved is hope or belief, there is no ground for regarding contractual trust as Faulkner's 'metaphysical hybrid of attitude and action'.

${ }^{4}$ Whether believing that Y has a commitment is belief realistically understood is, of course, controversial. Meta-ethical expressivists will deny it. A relevant fact here is that we can speak of betrayal of trust.
} 
The second piece of evidence Faulkner appeals to comes from considering distrust. He notes that we in fact have no use for the three-place predicate ' $\mathrm{X}$ distrusts Y to V', ${ }^{5}$ though Hawley attempts to define it. ${ }^{6}$ Yet we distinguish between not trusting and distrusting, just as we do between not believing and disbelieving. But, on the suggestion I have made this distinction can be drawn. The suggestion is that threeplace trust is a certain kind of conjunctive belief. But though disbelief is a form of belief (belief that it is not the case that ...) distrust is not a form of trust. Rather distrust consists in a complex of belief and doubt.

In Faulkner's example, I do not trust the car mechanic to deliver the mail, as he says, but this does not involve any distrust, since I do not believe he has any commitment to deliver the mail. But if I do not trust the mailman to deliver the mail this does involve distrust, since I believe he is committed to doing so. What this distrust consists in is my doubting whether he can be relied upon to meet the commitment I believe he has (perhaps because I believe that he is scared of the dog).

So distrust can be thought of as 'an attitude in its own right', as Faulkner insists, even if the one-place and two-place notions of trust are not thought of as basic relative to the three-place notion so long as that is not thought of as having a metaphysically hybrid nature. Distrust is not the same type of attitude as trust, as disbelief $i s$ the same type of attitude as belief; it is not a type of conjunctive belief, but it is still just a complex attitude, one of belief and doubt, not a metaphysical hybrid of an attitude and an action. ${ }^{7}$ The contrast between disbelief/belief on the one hand and distrust/trust can be maintained even if Faulkner's claim that contractual trust is metaphysically hybrid is rejected.

Still on the topic of distrust Faulkner adds that though while thinking of contractual trust, trust and distrust are contraries not contradictories, removing trust from a case in which it is present can result in distrust. This is true. In the situation he considers I trust the car mechanic to give an honest quote, so I do not bother to shop around for another. That is, on the proposal about contractual trust I have suggested, I believe that he is committed (as a professional tradesman) to giving me an honest quote and believe that he can be relied upon to meet that commitment. If I cease to believe the second of these things, I move from trust to distrust, as Faulkner says. But absent his false assumption that contractual trust is a metaphysical hybrid I fail to see how this is relevant to his main contention. 'Relatedly,' Faulkner writes, 'we tend not to trust people not to do things'. This is a verysurprising claim. I trust my wife not to have an affair, for instance. But Faulkner gives an argument for his claim so we must look at it. What he says about this type of case is that such trust is peculiarly self-defeating since 'to trust [her] not to have an affair would be to draw [her] attention to the fact that you do not presume [she] will not' (my italics). But this is a terrible argument. Of course, it would not be my trusting her, but my announcing

\footnotetext{
5 And a Google search turns up no instances.

${ }^{6}$ Her definition is: To distrust someone to do something is to believe that she has a commitment to doing it and yet not rely upon her to meet the commitment.

${ }^{7}$ Perhaps it is a hybrid of an attitude and inaction, since if I doubt whether someone is to be relied upon I will not rely upon them (unless needs must).
} 
my trust that would draw her attention. So I do not announce my trust. As Faulkner says, some reassurances are notreassuring. So I do not see that Faulkner's reasoning supports his surprising claim that we tend not to trust people not to do things. Anyway, his conclusion from all this is only that a proper account of the relation of trust to distrust requires a purely attitudinal, non-hybrid, conception of trust to be taken as basic - but I can agree with that since I have argued that contractual trust does not require an action component as a metaphysical necessity.

The fourth piece of evidence Faulkner offers for his position is the relationship between trustworthiness and trust, a connection he says is broken if three-place trust is conceived as hybrid. He describes the following sort of case. My wayward teenage son demands the car keys. Fairly, judging the (bad) consequences of handing them over, I refuse. My son judges me as failing in trustworthiness, as being blind to his needs. He is wrong, but, Faulkner says, he would not be 'if trustworthiness is identified by reference to trust'. So 'trustworthiness cannot be defined with respect to trust if trust is conceived contractually, or as three-place'. However, 'the analytical connection between trust and trustworthiness is preserved if trust is taken to be merely an attitude'.

This is unconvincing. Given that I do not fail in trustworthiness in this case - as Faulkner and I agree - the question is whether this can be explained if trustworthiness is explained via contractual trust. Faulkner thinks not since he thinks contractual trust is a hybrid. But I think this is wrong. Contractual trust is not a hybrid, it is merely an attitude and trustworthiness can be explained in terms of it. Whether I am trustworthy is fixed, I think, by the facts of the form ' $\mathrm{X}$ correctly trusts $\mathrm{Y}$ to $\mathrm{V}$ '; equivalently by facts of the form ' $\mathrm{Y}$ is committing to $\mathrm{V}$-ing and can be relied upon to meet that commitment because of his recognition of it'. As a father I have a range of commitments to my son. I am trustworthy in that role if I can be relied up to meet those commitments because of my recognition of them. One of them is not to provide him with the means to put himself into danger, even if he asks me to do so. In refusing the car keys I do not fail in trustworthiness, as Faulkner and I agree, but this does not show that trustworthiness cannot be defined by reference to contractual trust, understood, as I have argued it should be, as merely an attitude.

Faulkner's final piece of evidence is the existence of infant trust, which cannot consist in contractual trust because infants lack the necessary concepts and reasoning abilities. Of course, as noted already, what we call 'trust' is sometimes what is referred to in the literature as 'mere reliance'. I trust the bookcase to bear the weight of the books, that is, I believe it will (whether or not I actually put them on it). ${ }^{8}$ The dog trusts its master to feed it every morning (or trusts, every morning, its master to feed it), that is, it so believes. We trust some politicians to make fools

\footnotetext{
${ }^{8}$ Of course, my attitude towards the bookcase can be one of contractual trust if, for example, I believe that it is person magically transformed but retaining agency (think of the 'Beauty and the Beast' scenario). Contractual trust is an attitude and whether I can take that attitude to something does not depend on its nature but only on what I think is its nature. Hawley sometimes writes as if contractual trust can only be directed towards actual persons, e.g., 'we often rely upon inanimate objects but we do not grant them the rich trust we sometimes grant one another' (Hawley 2014: 2), but since this is obviously not so she must be understood to be writing (entirely appropriately) elliptically and intending to refer not to actually merely inanimate objects but to what we think of as merely inanimate objects.
} 
of themselves, that is, we believe they will. I trust my disliked departmental colleague to do me down at every opportunity, that is, I believe that he will. The infant trusts its mother as the dog trusts its master. The trust here is three-place but need not involve any action component. It is just a non-conjunctive belief of the form ' $\mathrm{X}$ believes that $\mathrm{Y}$ will V' (the dog believes that its master will put food on the floor). So, of course, if contractual trust is the conjunctive belief suggested, that $\mathrm{X}$ believes that $\mathrm{Y}$ is committed to $\mathrm{V}$-ing and can be relied upon to meet that commitment because he recognises that he has it, it entails that $\mathrm{X}$ believes that $\mathrm{Y}$ will V. My attitude to the bookcase is not contractual trust because it is not the right sort of conceptually sophisticated conjunctive belief. The same is true of the infant's attitude to its mother, and the dog's to his master. Once again, Faulkner points to no phenomenon that cannot be explained with the three-place notion of trust taken as basic.

In sum, Faulkner gives no good reason to think that contractual, three-place, trust is a metaphysical hybrid of attitude and action, and there are counterexamples to this. We can regard it, for all he says, as a certain form of conjunctive belief, not a hybrid of attitude and action. Distrust is also not an attitude-action hybrid, it is a complex of belief and doubt. And Faulkner has given no reason to doubt that twoplace and one-place trust are derivative from three-place trust.

Open Access This article is licensed under a Creative Commons Attribution 4.0 International License, which permits use, sharing, adaptation, distribution and reproduction in any medium or format, as long as you give appropriate credit to the original author(s) and the source, provide a link to the Creative Commons licence, and indicate if changes were made. The images or other third party material in this article are included in the article's Creative Commons licence, unless indicated otherwise in a credit line to the material. If material is not included in the article's Creative Commons licence and your intended use is not permitted by statutory regulation or exceeds the permitted use, you will need to obtain permission directly from the copyright holder. To view a copy of this licence, visit http://creativecommons.org/licen ses/by/4.0/.

\section{References}

Faulkner, P. (2015). The attitude of trust is basic. Analysis, 75(3), 424-429.

Hawley, K. (2014). Trust, distrust and commitment. Nous, 48, 1-20.

Publisher's Note Springer Nature remains neutral with regard to jurisdictional claims in published maps and institutional affiliations. 